\title{
AGENTES MORAIS E A IDENTIDADE DA FILOSOFIA DE HUME
}

\author{
Flavio Williges* \\ fwilliges@gmail.com
}

RESUMO A interpretação padrão da filosofia de Hume o apresenta como um cético radical acerca das pretensões da razão em fundamentar adequadamente nosso sistema de crenças e, ao mesmo tempo, como um naturalista que procurou sustentar que nossas crenças, embora racionalmente infundadas, não podem ser abandonadas na vida comum, em função da ação de sentimentos e impulsos naturais. Este trabalho pretende mostrar que o naturalismo de Hume pode e deve ser interpretado como uma metodologia de abordagem de conceitos filosóficos (ideias e crenças, no vocabulário de Hume) que incorpora elementos irrefletidos da vida comum (como sentimentos e impulsos naturais) e atribui a tais elementos o mesmo estatuto teórico que processos abstratos como raciocinios e argumentos. Uma filosofia que legitima mecanismos não-reflexivos no tratamento de problemas filosóficos é chamada por Hume de "filosofia verdadeira". Tal espécie de filosofia é incompativel com formas radicais de ceticismo, pois mecanismos irrefletidos que originam ideias são imunes à dúvida. Para exemplificar as teses aqui defendidas e tornar minha caracterização do naturalismo mais convincente, faço uma rápida descrição, ao final do artigo, da abordagem abrangente dos agentes morais por Hume.

Palavras-chave naturalismo, ceticismo, Hume, ação moral, sentimentos

* Professor do Departamento de Filosofia da Universidade Federal de Santa Maria (UFSM). Artigo recebido em 05/12/2011 e aprovado em 26/12/2011.

KRITERION, Belo Horizonte, nº 124, Dez./2011, p. 397-415. 
ABSTRACT The standard interpretion of Hume's philosophy presents him both as a radical skeptic regarding rational claims about the adequate foundation of our belief system and as a naturalist who maintained that our beliefs (though rationally ungrounded) cannot be given up in ordinary life, due to natural drives and sentiments. This paper purports to show that Hume's naturalism can and should be interpreted as a method for addessing philosophical concepts (ideas and beliefs, to use Hume's jargon) that incorporates unreflected elements ofordinary life (such as natural sentiments and drives) and assigns to them the same theoretical status that abstract processes such as reasons and arguments have. A philosophy that warrants unreflected mechanisms in the treatment of philosophical problems is what Hume calls a "true philosophy". Such philosophy is compatible with the more radical forms of skepticism, because the unreflected mechanisms that bring about ideas are imune to doubt. To ilustrate the theses put forth here and so as to render my characterization of naturalism more persuasive, I describe briefly and in broad terms at the end of the paper Hume's view of moral agency.

Keywords naturalism, scepticism, Hume, moral action, sentiments

\section{Introdução}

Em 2011 comemoram-se os 300 anos de nascimento do filósofo David Hume. Ao longo desses trezentos anos não faltaram divergências entre intérpretes sobre a natureza da filosofia humeana. A tradição interpretativa mais antiga, que remonta a James Beattie, considerava Hume um defensor de um ceticismo radical, alguém que viu nos argumentos céticos uma oportunidade para estabelecer um ceticismo corrosivo que não deixaria qualquer possibilidade de justificação racional das crenças do senso comum ${ }^{1}$. Os argumentos céticos empregados por Hume no Tratado e na Investigação foram tomados, nessa tradição, como ferramentas para demolir as estruturas de pensamento que originam as crenças humanas mais fundamentais, como a crença que objetos possuem uma existência contínua no tempo e são independentes da mente ou percepção humana, a crença que interações causais

1 Beattie afirma que "o ceticismo é uma coisa boa, à medida que tende a tornar os homens bem-educados, de boa índole e libertá-los do pedantismo e da petulância. Existem alguns tipos de ceticismo que realmente tem essa tendência". Segundo Beattie, o ceticismo de Hume, no entanto, não é dessa espécie: "Mr. Hume, de modo menos reservado que qualquer um de seus predecessores, avançou léguas na demolição do senso comum". 
observadas permanecerão inalteradas no futuro e a crença na existência de um "eu" que acompanharia a transição de percepções no teatro mental.

Na metade do último século, a leitura cética deu lugar à interpretação naturalista defendida originalmente por Norman Kemp Smith ${ }^{2}$. A principal inovação da leitura de Kemp Smith foi considerar que o essencial da filosofia de Hume residiria na doutrina das crenças naturais ou instintivas, de modo que o ceticismo desempenharia no seu sistema uma função meramente instrumental e secundária: abrir caminho para o naturalismo. Hume não seria, segundo Kemp Smith, propriamente um filósofo cético, mas um naturalista interessado em mostrar que a crença não é determinada por raciocínio e argumento, mas pelo instinto natural ou sentimento.

Os avanços provocados pela interpretação naturalista de Kemp Smith originaram novas tradições de leitura do ceticismo e naturalismo humeano. Algumas versões mais nuançadas do ceticismo foram apresentadas ${ }^{3}$, permitindo estabelecer uma imagem mais rica da filosofia de Hume. Esse movimento de constante retorno e revisão das interpretações favorecidas no passado ainda está em curso, mas algumas interpretações lentamente estão se tornando interpretações padrão ou standard da filosofia de Hume. Nesse ensaio pretendo caracterizar aquela que considero ser a tradição de leitura mais comum na atualidade em torno da natureza do ceticismo e do naturalismo de Hume e indicar algumas tensões ou aspectos dessa tradição de abordagem que, suponho, merecem um maior debate. Os pontos que pretendo discutir são estes: a) a atribuição a Hume de um ceticismo radical sobre a capacidade da razão humana justificar certas crenças fundamentais do nosso "sistema de crenças", b) a caracterização do naturalismo como uma doutrina causal sobre a formação da crença, o que implica em conceber a filosofia de Hume como uma filosofia psicológico-descritiva, ao estilo do naturalismo científico dos nossos dias ${ }^{5}$.

2 KEMP SMITH, N. The philosophy of David Hume. New York: Macmillan Press, 1964.

3 No artigo A tendência do ceticismo de Hume Robert Fogelin (2007) apresenta pelo menos três tendências distintas que podem ser reconhecidas no ceticismo de Hume. Outra leitura bastante original do ceticismo de Hume pode ser encontrada no livro do Prof. Plinio Smith, O ceticismo de Hume. Smith procura mostrar que elementos naturalistas já estariam incorporados no ceticismo humeano, de modo que não se poderia falar do ceticismo e do naturalismo como dois momentos distintos (um negativo e outro positivo) do pensamento filosófico de Hume. Hume seria, segundo Plinio, um filósofo cético,mas o ceticismo humeano seria, ele mesmo, um naturalismo. (SMITH, 1996, p. 197).

4 A crença de que temos um eu, vivemos em um mundo de objeto que mantêm interações causais entre si no espaço-tempo, que existem substâncias, que existem ações "boas" e outras ações que são "más" constituem parte daquilo que chamarei de "nosso sistema de crenças" ou do "esquema conceitual" que adotamos para organizar nossa experiência. Boa parte da filosofia de Hume pode ser lida como um esforço para tornar essa estrutura mais transparente ou conspícua.

5 Essa caracterização do naturalismo tem sido defendida por Kemp Smith (1966) e Stroud $(2008,1984)$. Stroud afirma, a favor da interpretação da crença como um processo causal resultante da interação mentemundo que "toda crença em questão de fato e existência real é simplesmente o resultado necessário 
Contra esses dois aspectos da interpretação padrão de Hume, pretendo sustentar que a doutrina naturalista, mais do que ser uma teoria causal da crença, é uma estratégia metodológica geral de abordagem de problemas filosóficos adotada por Hume, a qual resulta na incorporação de itens considerados espúrios pelas filosofias racionalistas da época. Conforme pretendo mostrar, o naturalismo de Hume legitima o apelo a um conjunto de dados muito mais amplo do que "as verdades auto-evidentes da razão". ${ }^{6}$ Se esse ponto for correto, Hume não pode, igualmente, ser tomado como um cético radical (como a interpretação padrão apregoa), pois sua visão metodológica altera profundamente o sentido do que é uma explicação filosófica e, portanto, igualmente das condições que tornam plausível essa forma de ceticismo, sobretudo a ideia de uma dúvida abrangente, que poderia ser lançada contra as fundamentos do pensamento e da ação humana.

\section{A leitura padrão do ceticismo e naturalismo de Hume}

Nas interpretações mais recentes de Hume, representadas, dentre outros, por Strawson (1985), Williams (1995), Stroud (1984, 2008), ceticismo e naturalismo não são mais tratados como posições independentes, mas complementares: Hume seria um cético por defender a impossibilidade de uma justificação racional de crenças básicas (causalidade, mundo exterior e "eu”) e um naturalista por afirmar que essas crenças humanas fundamentais, injustificáveis pela razão, independem de argumento e sempre retornariam tão logo deixássemos as reflexões próprias ao registro da epistemologia. A convivência dessas duas orientações ampara-se na dualidade de registros em que a análise das crenças se desdobra: o nível de análise crítico-filosófico e o nível empírico-ordinário. O ceticismo universal imperaria no nível crítico, da reflexão filosófica extenuante, de gabinete, e o naturalismo no nível empírico, da vida comum. No nível crítico, como diz Strawson, "Hume nos deixa com um

de uma mente receptiva situada em certas circunstâncias". Conforme Kemp Smith, [Na epistemologia] "como, na esfera da ética e estética, a função da investigação filosófica, como Hume a concebeu, não é justificar nossas crenças últimas, mas apenas traçar suas fontes na constituição da natureza humana e mostrar como as crenças, auxiliadas pela razão, embora elas próprias sejam diretivas, condicionam e tornam possível a experiência de fato, que é o tema da filosofia e pelo qual seus julgamentos podem ser testados". (1966, p. 458).

6 Descartes afirma, nos Princípios de Filosofia, que a filosofia é um sistema de conhecimento completo, construído a partir de primeiras causas ou primeiros princípios claros e evidentes. Hume pretende mostrar que os princípios que constituem a filosofia são, de longe, menos claros e evidentes do que somos tentados a imaginar e, dependem, em grande medida, de mecanismos sensíveis, inteiramente alheios aos comandos da razão. Cf. DESCARTES, R. Carta do autor ao tradutor francês dos Princípios de Filosofia, ao jeito de prefácio. Lisboa: Edições 70, 1997. p.15. 
ceticismo irrefutado" (Strawson, 1985, p. 13). Michael Williams afirma, mais enfaticamente, que quando refletimos sobre nossas práticas e procedimentos o naturalismo dá lugar ao "ceticismo total, uma completa inabilidade para ver certezas cotidianas, inferências e julgamentos como merecendo algo remotamente semelhante ao status que nós, de outro modo, sem nenhum esforço, atribuímos a elas" (Williams, 1997, p. 8). Esse ceticismo radical que aparece nos momentos de reflexão filosófica é superado pelo naturalismo que garante a preservação ou sustentação instintiva das crenças naturais. Segundo Strawson, Hume "admitiria que no nível do pensamento filosófico-crítico nunca poderíamos oferecer nenhuma segurança contra o ceticismo, enquanto que no nível empírico, no qual as pretensões do pensamento são completamente supridas pela Natureza, teríamos um compromisso inescapável com a crença natural" (Strawson, 1985, p. 13). Em suma, a filosofia de Hume poderia ser descrita como uma filosofia naturalista e cética, onde o naturalismo estaria contido na ideia de que por graça da Natureza somos constantemente forçados a crer, embora, filosófica ou teoricamente, Hume esposaria um ceticismo universal ou total, que imperaria em todas as ocasiões em que abandonássemos as urgências da vida comum para filosofar?

Considerada num plano de visada geral, a tradição mais recente de comentário de Hume possui grandes vantagens em relação às interpretações sectárias que enfatizam ora o naturalismo, ora o ceticismo. Nela ficam preservadas duas orientações que encontram um forte suporte textual, sem, aparentemente, originar maiores embaraços filosóficos ou interpretativos. Não obstante isso, alguns pontos de tensão em torno do entendimento do modo pelo qual naturalismo e ceticismo se relacionam na filosofia de Hume podem ser identificados. Isso fica particularmente claro quando adentramos nas caracterizações mais precisas do ceticismo e do naturalismo. Como atribuir a

7 Uma formulação útil e detalhada desse mesmo ponto encontra-se na seguinte passagem de Di Pierris (2002, p.502): "Ele (Hume) coloca entre parênteses nossas crenças naturais e propensões a fim de investigar suas fundações do ponto de vista da sua versão da teoria tradicional das ideias herdada de Descartes, Locke e Berkeley. Esta espécie de reflexão cética radical é empreendida apenas raramente, nos confins do estudo (p.e.na conclusão do livro I do Tratado), e requer extenuantes contorções da mente (p.e, T 185-186). Essa reflexão conflita com nossas tendências naturais e crenças e, em particular, conduz ao resultado de não podermos fornecer às nossas crenças naturais fundamentais a espécie de justificação ultima que a reflexão cética radical exige. As conclusões céticas negativas da reflexão pirrônica não podem, portanto, ser integradas com as crenças instintivamente fundadas que mesmo o pirrônico é forçado a ter quando ele é resgatado pela Natureza. Ainda, embora o ceticismo radical não possa ser integrado com nossas crenças naturais, Hume endossa inteiramente essa forma de ceticismo enquanto ele está imerso no mesmo. Há, assim, uma dualidade emergindo da adoção de duas estruturas mentais não simultâneas que conduzem a resultados irreconciliáveis. A despeito da mútua exclusão, a possibilidade de flutuar de uma para a outra permanece: a "Natureza" não pode ser suprimida por muito tempo, enquanto que, do outro lado, a possibilidade de cair na "melancolia filosófica" também não pode ser erradicada completamente". 
Hume posição filosófica do ceticismo moderado se nos instantes de reflexão filosófica é o ceticismo radical que governa nossas mentes e, quando não estamos no registro da filosofia, a natureza torna-se a soberana? A solução costumeira consiste em dizer que o ceticismo mitigado não é um conjunto de "verdades ou doutrinas": "é algo que descobrimos estar conosco ou um estado em que descobrimos estar, quando as reflexões levando ao ceticismo excessivo foram temperadas ou mitigadas por nossas inclinações naturais" (Stroud, 2008, p. 180). Mas se a natureza não atua quando exercemos nossa razão, como ela amenizará o ceticismo excessivo a fim de tornar-nos céticos moderados em nossas investigações filosóficas? Ainda, como não transformar, através da caracterização do naturalismo como uma doutrina causal, Hume num irracionalista ou determinista acerca de aspectos centrais de nosso esquema conceitual? Essas dificuldades interpretativas se radicalizam ainda mais quando tratamos de entender o fenômeno da evanescência da dúvida cética frente à força dos instintos naturais, isto é, o fenômeno da flutuação de um estado de dúvida e descrença geral para um estado de espírito caracterizado pela admissão cega daquilo mesmo que, racionalmente, mostrou-se infundado. $\mathrm{Na}$ filosofia de Hume, segundo a interpretação de Strawson e Williams, a natureza bloqueia a suspensão do juízo. O ceticismo radical de Hume não gera um estado de suspensão do juízo, pois o potencial destrutivo dos argumentos céticos é contrabalançado pela natureza. Mas esse efeito supõe que ceticismo e naturalismo sejam duas forças poderosas e de igual peso atuando sobre nós. Chamemos essa tese de tese da simetria de forças entre ceticismo e naturalismo. Assumindo essa tese, o homem aparece como um ser cindido ou dividido pela atuação das forças contrárias do sentimento e da razão. A flutuação vivida em nossos espíritos é uma flutuação entre um estado de ceticismo radical e inquestionável para um estado de crença cega, igualmente inquestionável. Razão e natureza são iguais e, em seus registros de atuação, anulam uma a outra. Esse tipo de caracterização do ceticismo e naturalismo como pólos opostos, não comunicáveis e que se neutralizam em seus domínios não parece permitir uma compreensão adequada de aspectos fundamentais da filosofia de Hume, sobretudo da integração existente entre naturalismo e ceticismo e do lugar que a razão desempenha no naturalismo humeano. O ponto foi formulado com precisão por Livinstong:

Ao esboçar uma dicotomia radical entre razão e crença natural, deixa-se pouco lugar para refinamentos no conceito de razão que devem ser feitos se pretendemos fazer uma avaliação adequada da função que o pirronismo desempenha na filosofia de Hume. Pois a dicotomia entre razão e natureza tem deixado na mente de muitos a crença que, para Hume, a razão é pirroniana e que a crença natural corre livre, descontrolada e não monitorada por algo que poderia ser chamado de crítica racional. 
Isso nos capacita a migrar da imagem de Hume como um cético subversivo para a imagem dele como um irracionalista para quem todo pensamento é determinado por sentimento $(1984, \text { p. } 27)^{8}$.

Como a passagem revela as leituras que passaram a reconhecer e destacar a função do sentimento na filosofia de Hume e que pretendiam, ao mesmo tempo, superar a imagem dele como um cético corrosivo, acabaram por transformá-lo num naturalista-irracionalista. Igualmente, ao preservar um ceticismo radical, que apareceria como a concepção definitiva de Hume sobre os poderes da razão humana, essas leituras impedem uma apreciação adequada do ceticismo moderado na filosofia humeana. Como pretendo argumentar, ambos os direcionamentos interpretativos não parecem caracterizações adequadas dos propósitos filosóficos de Hume, pois ao mostrar que crenças humanas fundamentais independem de argumento, Hume não pretende reduzir a crença a um processo mecânico e inteiramente independente da reflexão racional. Ele tampouco pretende apresentar um ceticismo radical acerca do papel da razão na justificação de nossas crenças. Ao chamar a atenção para as crenças naturais, ele pretende instituir um novo modelo de abordagem dos conceitos gerais examinados pela filosofia e, por conseguinte, um novo modelo de justificação ou entendimento desses mesmos conceitos. Esse modelo é chamado por Hume, às vezes, de "verdadeira filosofia", "justa filosofia", em substituição à filosofia falsa e adulterada. Segundo Livingston, a verdadeira filosofia reconhece "a autoridade do sistema popular em seu próprio pensamento". Enquanto a filosofia falsa pretende se emancipar inteiramente da vida comum, a filosofia verdadeira começa dentro da estrutura da vida comum (Livingston, p. 24). Livingston também considera que a função do naturalismo não é afirmar que "uma pessoa é forçada a acreditar 'em qualquer coisa que a natureza o leve a acreditar, nem mais, nem menos'. Sua função é, antes, iluminar a natureza da verdadeira filosofia" (p. 28). Se for plausível interpretar o naturalismo nessa direção, ou seja, na direção de uma perspectiva de análise de nosso sistema de crenças caracterizada, essencialmente, pela aceitação do primado da vida comum (com seus hábitos, paixões e sentimentos) na filosofia, a representação do homem resultante não é de "deus dotado de razão" ou de um "cérebro desencarnado", mas de pessoas com ossos e sangue, que possuem amigos, afazeres, diversões e que, no curso de suas vidas, podem se interessar por questões metafísicas (do tipo que os filósofos costumam investigar), pensar

8 A causa primordial do desvio das leituras naturalistas, segundo Livingston, é a ênfase indevida no modelo causal de interpretação do naturalismo. 
em argumentos para lidar com elas e reconhecer o espaço restrito (porém, insubstituível), que a razão ocupa em nossas vidas. O naturalismo permite reconhecer, além da importância da razão e raciocínio, que forças animais, como sentimentos e paixões, desempenham um papel relevante na estruturação de nossa teoria geral do mundo e de nosso próprio auto-entendimento. $\mathrm{Ou}$ seja, se a sugestão que pretendo apresentar for correta, em vez de ser uma teoria mecanicista da crença e uma espécie de ceticismo radical sobre os poderes da razão, é o homem e a vida comum que "a filosofia verdadeira" de Hume pretende defender, modificando, dessa forma, a própria fisionomia da atividade filosófica. Um bom exemplo disso é o tratamento que Hume dá à moralidade. O sistema moral era considerado, por diferentes contemporâneos de Hume, como uma dádiva dos céus para a salvação do homem. A abordagem de Hume da moralidade mostra que a vida moral é um desses lugares onde o sentimento tem um papel crucial a ser levado em conta pela teorização filosófica. $\mathrm{O}$ apelo humeano a instintos e sentimentos, que constitui o ponto nodal do naturalismo, tem o propósito, nesse sentido, de enfraquecer a imagem da filosofia como uma disciplina justificadora e responsável por fornecer, no domínio prático, uma fundamentação inteiramente racional e segura de nossas crenças morais, especialmente sobre a capacidade de a razão ditar as regras que serão obedecidas pela vontade. Hume foi o defensor de uma concepção deflacionária do lugar da razão no nosso sistema de crenças (portanto, também da atividade racional da filosofia) e um introdutor de princípios sensíveis como elementos constitutivos de funções preponderantes em nossa condição, no pensamento, mas, sobretudo, na moralidade e política. Nesse sentido, o apelo aos princípios naturalistas ou instintivos não pretende aplacar a razão (gerando um ceticismo radical), mas instituir um novo padrão de racionalidade filosófica ou uma nova forma de entender o lugar da razão na filosofia. Existem muitas maneiras de apresentar o novo padrão de racionalidade instituído por Hume. A hipótese de leitura que pretendo perseguir consiste em afirmar que a racionalidade instituída pela entrada em cena do naturalismo é pragmáticooperativa, isto é, é motivada por um padrão de abordagem que fixa a atividade justificadora da filosofia como determinado pelo "esquema prático da vida", ou seja, pelos propósitos e objetivos práticos que perseguimos na vida moral e cognitiva ${ }^{9}$. Tal abordagem se opõe claramente as tendências que super-

9 Talvez a melhor maneira de entender a tese que estou procurando atribuir a Hume e que identificaria aquilo que ele chama de verdadeira filosofia é pensar na distinção cartesiana entre uma "investigação da verdade" (certeza metafísica) e a "conduta da vida" (certeza moral). A certeza metafísica é a certeza resultante da impossibilidade da dúvida. Para esse tipo de certeza, o sonho é uma hipótese que merece ser considerada, pois "não se pode negar, a menos que sejamos desarrazoados, que é motivo suficiente, 
intelectualizam ou buscam uma fundamentação puramente racional para nosso sistema de crenças (Descartes), fazendo da atividade filosófica racional um juiz da nossa imagem do mundo e de nós mesmos e também àquelas que transformam os princípios da filosofia em princípios naturais que atuam como forças cegas geradas causalmente (Stroud), fazendo da filosofia um mero registro e classificação dos mecanismos causais das operações naturais.

\section{O sentido do naturalismo de Hume}

$\mathrm{Na}$ abertura da seção II, da parte IV, do livro I do Tratado, ao comentar a crença na existência do corpo, Hume observa que o cético assentirá ao princípio concernente à existência do corpo, embora não possa "por qualquer argumento de filosofia" manter sua veracidade (T. 187). Na Investigação, ele manifesta, sobre este mesmo assunto, que se trata de um "tópico em que os céticos mais profundos e mais filósofos sempre irão triunfar." $(\mathrm{E}, 153)$ Com respeito a causalidade ele diz que "nenhum argumento demonstrativo" e nenhum argumento da experiência é capaz de "provar que o passado é semelhante ao futuro" (T, 89; E, IV, ii)

Tais amostras de pessimismo quantos aos poderes da razão (e várias outras que poderiam ser apresentadas) levaram muitos intérpretes de Hume a afirmar a tese de que ele seria um defensor da impossibilidade de uma justificação racional de nossas crenças últimas e que o ceticismo seria a resposta definitiva acerca de sua caracterização dos conceitos mais gerais que estruturam nossa imagem do mundo e do homem. A descrição das operações do entendimento humano que originam crenças levou Williams a afirmar que o ceticismo "é o veredicto final e inescapável em nossas pretensões ao conhecimento do mundo". (Williams, 1997, p. 2). A suposta defesa de Hume da invulnerabilidade teórico-filosófica do ceticismo traz consigo ainda uma tese sobre o lugar do naturalismo no sistema humeano. Como a passagem de abertura da parte IV

para não estarmos inteiramente seguros a respeito [de que haja corpo, estrelas e terra], o fato de se advertir que podemos do mesmo modo imaginar, quando adormecidos, que temos outro corpo, que vemos outros astros, outra terra, sem que na realidade assim o seja" (1975b, p. 50). Como Descartes coloca nos Princípios, "quem nunca esteve em Roma não duvida que não seja uma cidade da Itália, apesar de ser possível que todos aqueles que o informaram estavam enganados" (1997, p.276).Segundo Descartes, existem condições necessárias e suficientes para o uso de um conceito e essas condições são reconhecidas a partir de uma investigação puramente reflexiva. Saber, por exemplo, é incompatível com a falsidade. Como diz Descartes, posso pensar que a capital da Itália é Roma, por que sempre me disseram, mas, de um ponto de vista metafísico, é possível que não seja, pois todos poderiam estar enganados. Ele conclui daqui que somente temos uma certeza moral acerca desse assunto. Hume parece considerar que esse tipo de especulação e abordagem dos problemas filosóficos deveria ser temperado com o uso comum da razão. Nossas crenças e pensamentos não são independentes das condições práticas em que organizamos a experiência. 
do livro I sugere, o naturalismo de Hume deixaria o ceticismo intocado e mostraria que este, ainda que seja filosoficamente irrefutável, seria incapaz de levar-nos a repudiar nossas crenças no nível não reflexivo, empírico-ordinário, pois somos determinados pela Natureza a "viver, falar e agir como as outras pessoas nos assuntos comuns da vida" (T, 269), de modo que sequer se coloca a questão da renúncia de nossas expectativas indutivas, a suspensão da crença no mundo externo e na identidade do "eu". A filosofia de Hume combinaria assim um ceticismo e um naturalismo, onde o último "aparece como algo semelhante a um refúgio de seu ceticismo" (Strawson, p. 12) ${ }^{10}$

Não é difícil reconhecer o papel central que a razão, enquanto faculdade detentora de uma autoridade suprema sobre nossas crenças, ocupa nesse tipo de representação da filosofia de Hume. Ela aparece como a faculdade que responde pela análise das evidências disponíveis e pela legimitação ou condenação de nossa imagem geral do mundo natural e da vida em sociedade. Entretanto, como o fracasso dessa tarefa conduz diretamente ao ceticismo, que, segundo Hume, é contrário a própria razão (EHU, p.160), a Natureza é apresentada como a força capaz de suplantar a extinção de todo "grau de evidência" resultante da atuação do entendimento isolado (T, 267). Contra o caráter inteiramente destrutivo do ceticismo radical, a natureza atuaria ocupando o lugar da "inocência que, uma vez perdida, nunca mais é retomada" (Williams, p. 9). A inocência perdida foi revelada pelo ceticismo que ao destruir as pretensões da razão tornou patente a falta de fundamento de nossas crenças. Assim, o naturalismo de Hume seria como que um remédio paliativo para o ceticismo, um refúgio onde poderíamos nos abrigar da nossa incapacidade de defender "a razão pela razão" (T, 187). A orientação naturalista de Hume seria, em outras palavras, uma conseqüência lógica do malogro de seu percurso de pensamento em busca de fundamentos para crenças. Hume estaria interessado em fundamentar filosoficamente nossas crenças naturais na razão e, ao descobrir a ausência de fundamentos, teria adotado, como uma espécie de saída de emergência, o naturalismo.

Contra essa leitura, eu pretendo mostrar que os elementos naturalistas da filosofia de Hume, especialmente no Tratado, não são substitutos da razão

10 Também para Williams haveria esta dupla perspectiva: "a perspectiva [outllok] que nós naturalmente assumimos na vida comum que não envolve dúvidas sistemáticas profundas sobre a confiabilidade de nossos dados, a razoabilidade de nossas inferências, ou a objetividade de nossos julgamentos e a perspectiva [outllok] ao qual somos inevitavelmente conduzidos quando voltamos e refletimos sobre nossas práticas e procedimentos, que é o ceticismo total, uma completa inabilidade para ver certezas cotidianas, inferências e julgamentos como merecendo algo remotamente semelhante ao status que nós, de outro modo, sem nenhum esforço, atribuímos a elas" (WILLIAMS, 1997, p. 8). 
na explicação das crenças, mas parte de um novo modelo de racionalidade, um modelo caracterizado pela pretensão de mostrar que a fundamentação puramente intelectual dos aspectos mais gerais do nosso esquema conceitual (aqueles elementos que são objeto da ciência do homem de Hume) é uma exigência descabida e falsa, que poderia, sem nenhum prejuízo para a ciência e ação, ser integrada com princípios ligados à nossa natureza sensitiva e às nossas paixões ${ }^{11}$.

O naturalismo aparecerá aqui como parte da metodologia adequada de abordagem filosófica das principais crenças humanas. Nessa metodologia, conceitos centrais de nossa armação lingüística não são considerados legítimos somente se passarem no teste racional. Motivos fortes da vida sensível humana são equiparados com argumentos e raciocínios. Com isso, os princípios naturalistas enfatizados por Hume deixam de serem meros mecanismos causais de formação de crenças que ocupariam o lugar da razão e tornam-se parte da natureza de certos conceitos ${ }^{12}$. Essa fundamentação tem a forma de uma justificação que incorpora elementos não-racionais presentes em nossas atividades teóricas e práticas, no pensamento e na ação. A filosofia naturalista não é, nesse sentido, avessa a raciocínios. Como o próprio Hume diz: "o raciocínio exato e justo é o único remédio universal, adequada para todas as pessoas e todas as disposições e é o único capaz de subverter a filosofia abstrusa e o jargão metafísico (E, p. 12-13). Uma filosofia adequada aceita argumentos, mas também sentimentos suaves e moderados. "A filosofia, ao contrário, se adequada, somente pode nos apresentar sentimentos suaves e moderados e, se falsa e extravagante, suas opiniões serão meramente os objetos de uma especulação fria e geral (T, 271-272). Assim, raciocínio, argumento, juntamente com sentimentos, instintos e paixões, não são, para Hume, forças separadas, mas integradas num todo, como uma tela que envolve várias camadas sobrepostas, constituídas por diferentes materiais, e onde cada uma contribui para o efeito final. O naturalismo, assim entendido, é uma tentativa de reconhecer a autoridade filosófica que princípios irrefletidos da vida comum têm na rede de conceitos que formulamos para pensar o mundo. A fragilidade da razão, por sua vez, legitima um ceticismo moderado, um ceticismo que consiste em condenar sistemas metafísicos estabelecidos por

11 Hume denuncia essa espécie de filosofia quando diz, na Investigação (EHU, p.9) que os raciocínios profundos da metafísica "não são propriamente uma ciência, mas surgem, seja dos esforços infrutíferos da vaidade humana, que penetraria em assuntos completamente inacessíveis ao entendimento, seja da força das superstições populares, que, sendo incapazes de se defender em solo legítimo, levantam esses matagais cerrados para esconder e proteger sua fraqueza" (E, p. 11).

12 Cf. Livingston, p. 27. 
mera consistência lógica de conceitos e admitir forças estranhas à razão (como a história, a educação, os sentimentos). Esse ponto é claramente formulado quando Hume indica a espécie mista de vida recomendada pela sua filosofia. Essa espécie de vida é composta por uma mistura de reflexão e argumento com o reconhecimento de fatos gerais, empíricos, e ligados à nossa constituição como seres sociais e naturais.

Parece, então, que a natureza indicou uma espécie mista de vida como a mais adequada à raça humana e intimamente admoestou-os a não permitir nenhuma dessas tendências que atraem muito, de modo a incapacitá-los para outras ocupações e entretenimentos. Ceda a tuas paixões pela ciência, ela diz, mas permita que tua ciência seja humana e, como tal, possa ter uma referência direta à ação e sociedade. $O$ pensamento abstruso e as pesquisas profundas, eu os proibirei e punirei severamente, com a melancolia triste que eles introduzem, pela incerteza infinita que eles lhe envolvem e pela fria recepção que suas pretensas descobertas enfrentarão quando comunicadas. Seja um filósofo, mas, em meio à tua filosofia, seja ainda um homem” (EHU, p. 9).

Quando razão e sentimento são chamadas para atuar juntas temos um retrato do homem que não nega nossa natureza corpórea e sensível e não elimina completamente a função da razão, contribuindo para uma consciência mais clara dos princípios que atuam na natureza humana e na produção de uma reflexão filosófica mais habilitada a promover nossos propósitos de conhecimento e felicidade.

\section{Razão e ceticismo moderado}

Em $T$ 183, Hume pergunta se ele seria "um destes céticos, que sustenta que tudo é incerto e que nossos julgamentos não possuem nenhuma medida de verdade ou falsidade" e responde dizendo que esta questão é inteiramente supérflua, pois "nem ele, nem ninguém foi sincera e constantemente desta opinião". A sua explicação é então completada indicando a razão do uso cuidadoso de argumentos céticos em suas investigações. "Minha intenção então ao empregar cuidadosamente os argumentos desta seita fantástica é somente para tornar o leitor sensível à verdade de minha hipótese: que todos nossos raciocínios concernentes a causas e efeitos derivam-se tão somente do costume e que a crença é propriamente um ato da parte sensitiva e não da parte cogitativa de nossa natureza" (T 183). Aqui Hume indica claramente que é a pretensão filosófica de seu trabalho mostrar que os raciocínios causais não dependem da existência de algum fundamento de ordem racional e, para encaminhar esta recusa da razão e apresentar a fundação dos raciocínios de causa e efeito em nossa natureza sensitiva, são usados os argumentos "desta 
seita fantástica" chamada ceticismo. Além disso, em diferentes momentos, Hume chama atenção para o fato de que "a destruição da razão" que o cético pretende produzir não tem nenhum propósito especifico. Na Investigação, Hume descreve os argumentos céticos como "argumentos e raciocínios que têm tão pouca utilidade para qualquer propósito mais sério". (E, VII, 15 grifo meu). Em E VII, ii, 23, ele afirma que "a objeção mais importante e contudendente ao ceticismo excessivo é que nenhum bem duradouro pode jamais resultar dele enquanto gozar de sua plena força e vigor. Basta apenas perguntar a um desses céticos o que ele tem em mente e qual é o seu propósito com todas essas excêntricas indagações. Ele será imediatamente tomado de perplexidade e não saberá o que responder" (E, XII,ii, 23). Ao tratar dos argumentos de Berkeley referentes à abstração e às ideias gerais ele observa que esses argumentos são meramente céticos, ou seja, "não admitem nenhuma resposta e não produzem nenhuma convicção. Seu único efeito é causar aquela perplexidade, indecisão e embaraço momentâneos que são o resultado do ceticismo" (E, XII, i, 15n).

Uma rápida análise do contexto onde essas passagens encontram-se mostra claramente que elas fazem referência ao ceticismo radical, ao ceticismo que Strawson e Williams afirmam ser uma das disposições fundamentais da filosofia humeana. O ceticismo consiste aqui em argumentar que uma crença ou um conjunto de crenças é epistemicamente injustificável e somente pode ser superado pela força da natureza. É claro que, do ponto de vista reflexivo, essas passagens são insuficientes para mostrar que os argumentos céticos são inválidos ou enfrentam alguma dificuldade quanto à sua lógica interna. Haveria uma renúncia dos efeitos de persuasão do argumento em função das urgências da vida, mas do ponto de vista da lógica interna, suas conseqüências deveriam ser admitidas. Contudo, é um erro pensar que Hume não reconheceu limitações sérias e incoerências na própria lógica que leva ao ceticismo radical. Essa ideia aparece mais claramente naquelas passagens onde Hume associa os credos do ceticismo e dogmatismo. "A razão cética e dogmática são da mesma espécie" (T 187). O dogmático e o cético exigem que para cada proposição ou opinião sustentada deve haver pelo menos uma razão ou fundamento. Hume recusa tanto a razão cética que pretende expor a falta completa de fundamentos para nossas crenças e a razão dogmática, que acredita ser capaz de oferecer argumentos para tudo. Ambas, no entanto, são forças destruidoras da razão: a primeira por tentar destituir a razão de sua autoridade e a segunda por alimentar sistemas metafísicos sem sustentação na realidade. O objetivo de Hume é não é destituir a razão, mas permitir a introdução de uma razão humilde, uma razão, ao mesmo tempo, que combina curiosidade e desejo de 
conhecimento (e precisa ser freada nos seus anseios) com a consciência de seus próprios limites. Essa perspectiva de tratamento dos argumentos céticos encontra-se inequivocamente expressa na Carta de um Cavalheiro ao seu amigo de Edimburgo. Como se sabe, Hume escreveu a Carta em resposta a um panfleto, provavelmente escrito pelo reverendo Williams Wishart, então diretor da Universidade de Edimburgo. Wishart lançava seis acusações contra Hume, sendo a principal delas a de defender um ceticismo universal. Hume formulou a acusação que lhe foi dirigida dizendo que autor do Tratado sustentaria "um ceticismo universal" que duvidaria de "todas as coisas (exceto de sua própria existência) e sustenta a loucura de fingir não acreditar em nada com certeza" (C, 1994, p. 17). Ele responde a acusação dizendo que o ceticismo total não é uma posição séria, defensável e que a utilização que ele fez dos argumentos céticos teve como único propósito abater "os meros raciocinadores humanos". Tudo o que Hume pretende "com esses escrúpulos é abater o orgulho dos meros raciocinadores humanos, ao mostrar para eles que, mesmo no que respeita aos princípios que parecem mais claros e que eles devem necessariamente adotar a partir dos instintos mais fortes da natureza, eles não são capazes de alcançar uma consistência completa e uma certeza absoluta. Modéstia, então, e humildade com relação às operações de nossas faculdades naturais é o resultado do ceticismo, não uma dúvida universal que é impossível para qualquer homem sustentar e que o primeiro e mais trivial acidente na vida deve imediatamente desconcertar e destruir" (L, 1994, p. 17, grifo meu). Ou seja, Hume afirma que seu objetivo não foi rejeitar toda a certeza, mas apenas mostrar a "fraqueza e incerteza da mera razão humana", renunciando as pretensões de certos filósofos dogmáticos. A carta de Hume não parece deixar dúvidas: os argumentos céticos tem uma finalidade pedagógica e moral; eles se dirigem contra aqueles filósofos que sustentam haver uma certeza absoluta e uma consistência completa na justificação dos princípios de operação das faculdades humanas. É importante também observar que aqui, assim como no Tratado (T657), ele diz que não é uma dúvida universal a conseqüência dos argumentos céticos. Tanto o dogmatismo daqueles que acreditam no poder pleno da razão, quanto o ceticismo universal ou descrença completa na razão são incompatíveis com o ceticismo que Hume pretendeu defender ${ }^{13}$. Sendo o ceticismo universal claramente recusado, qual a natureza do ceticismo de Hume e por que ele adotou argumentos que poderiam levar e fracos, de acordo com as disposições sucessivas da mente. (T186) 
seus leitores, como ocorreu com o reverendo Wishart, a suspeitar de um ceticismo universal?

Um caminho de resposta possível poderia ser desenvolvido sustentando que os argumentos céticos radicais pretendiam destruir a confiança excessiva dos dogmáticos na razão, mas não destrui-la completamente. Entendidos nesse sentido, os argumentos céticos radicais teriam no sistema humeano uma função similar aquela visada por Descartes na Primeira Meditação. Na filosofia cartesiana, os argumentos céticos servem para preparar o caminho para uma epistemologia e uma metafísica centrada nos poderes da razão. Na filosofia de Hume, eles também são instrumentos metodológicos, porém destinados a enfraquecer a razão e permitir um ceticismo moderado, isto é, um ceticismo que aceita a operação de princípios racionais na filosofia, desde que devidamente corrigidos e educados. O enfraquecimento do ceticismo excessivo não resulta, assim, da atuação da natureza, mas da contemplação do fracasso da própria razão que, quando abandonada a si mesma cai em ruína (T, 225). O tipo de filosofia que Hume pretende desenvolver não tende, como é a pretensão dos argumentos céticos pirrônicos ou radicais, subverter os raciocínios da vida ordinária e levar dúvidas tão longe ao ponto de aniquilar toda a especulação e ação $(\mathrm{E}, \mathrm{V}, \mathrm{ii}, 2)$. Hume desaprova uma filosofia que não seja "humana". Na Investigação, Hume afirma que o pirrônico "quando desperta de seu sonho, é o primeiro a rir-se de si mesmo e a confessar que suas objeções são puro entretenimento, e só tendem a mostrar a estranha condição da humanidade, que está obrigada a agir, a raciocinar e a acreditar sem ser capaz, mesmo pelas mais diligentes investigações, de convencer-se quanto às bases dessas operações...”(E, XII, ii, p.23). Isso parece querer dizer, em primeiro lugar, que as teses do cético radical são indicações ou orientações para mostrar nossos limites cognitivos, porém não são teses substantivas assumidas por Hume acerca dos poderes cognitivos humanos. Um cético moderado aceita que a razão tem limites e reconhece que argumentos e raciocínios têm lugar na elaboração de uma filosofia justa e verdadeira. A razão tem uma função interrogadora e na correção das operações naturais do entendimento, é ela que nos ajuda a combater a indolência, a arrogância e a credulidade, ao mesmo tempo em que destitui o zelo e entusiasmo fanático resultante da atuação das paixões que contrariam as orientações racionais e morais $(\mathrm{T}, 270,271, \mathrm{E} 40,41)^{14}$. Hume distingue, quanto a isso, dois

14 O ceticismo moderado também é um antítodo contra o entusiasmo e o fanatismo religioso, que "produz as mais cruéis desordens na sociedade" e compartilham "o maior desprezo pelas regras estabelecidas da razão, da moral e da prudência" (Hume, 1980, p. 294) 
conjuntos de princípios associados à imaginação que parecem justamente permitir uma função limitada para a razão e que rebatem a interpretação do naturalismo como uma teoria sobre a formação causal das crenças: princípios universais e permanentes e os princípios mutáveis e irregulares. Ele diz: “eu separo na imaginação os princípios que são permanentes, irresistíveis e universais, tais como aquele da transição costumeira das causas aos efeitos, dos princípios que são mutáveis, fracos e irregulares.[...] Os primeiros são a fundação de todos nossos pensamentos e ações, de modo que sua remoção produziria imediatamente a ruína e o perecimento da natureza humana. Os últimos não são nem inevitáveis na humanidade nem necessários ou úteis na conduta da vida.[...] Por esta razão, os primeiros são aceitos em filosofia, e os últimos rejeitados" (T 225). Aqui, Hume afirma sua disposição de aceitar em filosofia princípios da imaginação que podem ser corrigidos pela reflexão. Estes princípios universais fundam "nosso pensamento e ação". Os princípios naturais corrigidos pela razão fundam um conhecimento empírico, informado pelas nossas necessidades e objetivos práticos. Numa carta enviada a Stewart, Hume afirma que existem "muitas espécies diferentes de certeza e algumas delas são satisfatórias para a mente humana mesmo não sendo talvez tão regulares quanto a certeza de tipo demonstrativo" (Hume apud Kemp Smith,1966, p. 413). Essa certeza que não é de caráter demonstrativo é a certeza ligada à experiência, às questões de fato, ou ainda, ao conhecimento empírico, o qual informa a ação ordinária e permite o desenvolvimento da ciência. Isso quer dizer que os princípios da imaginação podem ser justificados pela sua racionalidade empírica, isto é, uma racionalidade que não é equivalente a necessidade lógico-dedutiva, mas que exibe um grau satisfatório de rigor e supõe, até certo grau, a atividade da razão ${ }^{15}$. É essa certeza comparativa e suficiente para nossas finalidades que os princípios naturais exibem que os torna não-falaciosos. Além disso, Hume fornece indícios para pensar que a imaginação não é uma faculdade inteiramente livre. As Regras para Julgar de Causa e Efeito são uma representação clara disto. A razão orienta o instinto, nos conduzindo a refinar e elaborar nossos procedimentos indutivos e, muitas vezes, nos leva a rejeitar aquilo que nos achamos inclinados a aceitar. A pretensão da filosofia de Hume é, portanto, a de reconduzir a razão a sua função apropriada: como uma faculdade que atua juntamente com as operações naturais do entendimento e não como uma capacidade de julgar a experiência, estabelecendo a legitimidade de seus fundamentos últimos, tarefa fundamentos de uma ciência cética" do seu O ceticismo de Hume (1995). 
para a qual é incapaz. Assim, preserva-se o estatuto legítimo das máximas da vida comum, sem o apelo a uma fundamentação racional última destes princípios.

\section{Conclusão}

Nesse artigo procurei fornecer evidências que favoreçam uma interpretação da filosofia de Hume como sendo uma filosofia naturalista e cética. Interpretações tradicionais e muito comuns da filosofia humeana tendem a tomá-lo como um filósofo cético radical e um naturalista, no sentido que a crença é um produto da mecânica da realidade atuando sobre a inércia mental e o ceticismo uma teoria radical que sustenta que não podemos fornecer argumentos plausíveis para sustentar nossa visão geral da realidade. Procurei sugerir que o naturalismo de Hume pode ser corretamente interpretado como uma orientação geral de abordagem de problemas filosóficos que consiste em incorporar elementos sensíveis no interior do tratamento de problemas filosóficos. A principal evidência dessa perspectiva de tratamento encontrase na proposta humeana de uma filosofia verdadeira, uma filosofia que vê o homem como um animal, com corpo, identidade histórica, história natural e que reconhece sua fraqueza no controle racional da vontade. É essa abordagem abrangente que permite a Hume desenvolver uma caracterização do agente moral que não se assemelha a um calculador de ações que ajustamse a princípios abstratos de orientação da conduta. As ações morais, para Hume, decorrem de um caráter ou personalidade moral persistente no tempo. A vida moral, nesse sentido mais primitivo e pessoal, consiste em esculpir ou plasmar uma identidade ou personalidade moral. Almas virtuosos não são dadas. Elas são construídas, mas são construídas no interior de projetos de vida pessoais, que envolvem, não somente nossa racionalidade, mas todas nossas energias emocionais e sentimentos de compromisso e envolvimento, bem como sentimentos de separação e diferenciação frente aos outros seres humanos. Nesse aspecto, o corpo, o gênero, as expectativas e compromissos interpessoais e morais, que são parte da identidade moral de uma pessoa, contribuem para a definição da sua personalidade moral e da nossa concepção da virtude e do vício. Esse tipo de abordagem abrangente do agente moral representa aquele que tomo como sendo o protótipo mais adequado da dimensão naturalista da filosofia humeana. Fazer uma filosofia justa e adequada consiste em reconhecer esses aspectos de nossa vida comum, como nossa posição social, identidade de gênero, orgulho e outras paixões que atravessam nossa vida e suas funções no entendimento da virtude e do 
vício $^{16}$. Esse tipo de incorporação, aparentemente injustificada por um modelo racional de entendimento da moralidade, é explicada pelo reconhecimento dos limites do projeto de justificação racional de crenças do livro I e conseqüências da aceitação de uma abordagem filosófico-naturalista da moralidade nos livros II e III. Como afirma Baier (1994, p. 130, 131 e ss) uma pessoa deixe de ser, como na parte VI do livro I, um feixe de percepções que unem-se para formar uma vida. Uma pessoa:

"Sou eu e meus traços de caráter, eu e minhas habilidades, incapacidades, virtudes e vícios, eu e meu cérebro, coração, nervos, pele, poros, músculos, eu e minha vida, eu e meu feixe de percepções, eu e minha reputação, eu e minha família, eu e meus amores, eu e minhas ambições, eu e meu país, eu e meu local de férias favorito e seu clima..." (Baier, 1994, p. 135)

Uma filosofia verdadeira interessa-se por entender o conceito geral ou metafísico de pessoa, mas reconhece que tal entendimento, para uma filosofia justa e preocupada com questões morais, deve ser ampliado, incorporando princípios da vida comum. Ao fazer isso, Hume não faz mais do que aplicar os preceitos indicados na Introdução do Tratado, quando diz que "os princípios universais" obtidos por sua filosofia devem ser extraídos da "observação cuidadosa da vida humana, tomando-s como eles aparecem no curso comum do mundo, através do comportamento social do homem, nos seus afazeres e prazeres" (T, xix). Esse movimento, aparentemente inofensivo, constitui uma mudança completa no modelo de investigação filosófica adotado em seu tempo.

Eu procurei argumentar acima que a principal lição do naturalismo é metodológica: dar cidadania a conceitos tradicionalmente expurgados da filosofia;fazendo-nos ver que esses conceitos são centrais para uma abordagem compreensiva e adequada dos problemas filosóficos e que essa renovação da filosofia traz consigo inúmeras vantagens práticas (a principal delas talvez seja eliminar de vez todo jargão obscuro e enigmático dos sistemas vazios da metafísica, aqueles mesmos sistemas puros de pensamento que, se aplicados à vida política e social, nos levariam a mais completa ruína pela violência e rebelião dos fanáticos) . O naturalismo, entendido como a incorporação de itens da vida comum no pensamento filosófico, é a tendência central de uma filosofia purgada dos excessos metafísicos. Nessa filosofia, o intelecto

16 Nossa ideia de nós mesmos deve ter uma maior vivacidade do que nossas ideias de qualquer outra pessoa, em função de nossa consciência constante de nós mesmos. Essa vivaciade superior, alimentada pelo orgulho, transforma-se em simpatia para vivificar nossas ideias dos sentimentos dos outros, tornandose de impressões e sentimentos partilhados (T.320). 
humano tem uma função crucial, a função de corrigir nossa credulidade e a trivialidade das operações da imaginação. No entanto, esse modelo filosófico não nega a autoridade dos princípios naturais ou a relevância que fatos empíricos desempenham na análise filosófica de nosso sistema de crenças. É na filosofia prática de Hume que essa vinculação se mostrará mais claramente, onde sentimentos como o prazer e interesses práticos como a utilidade são chamados para compor a explicação dos fundamentos da moral. A finalidade da "verdadeira filosofia" é fazer a prática filosófica progredir metodologicamente em seu tratamento dos aspectos centrais de nossa condição, aproximando as descrições filosóficas da prática comum, dando realismo as suas representações e ampliando a consciência de nós mesmos e de nosso mundo.

\section{Referências bibliográficas}

FOGELIN, R. A tendência do ceticismo de Hume. Skepsis, n. 1, 2007, p. 99-118.

HUME, D. Treatise of Human Nature. Second Edition- Edited by Selbby-Bigge/Paul Nidditch. Oxford: Clarendon Press, 1978.

. Enquiries concerning to the Human Understanding and concerning the Principles of Morals. Third Edition. Edited by P. H. Nidditch. Oxford: Clarendon Press, 1975.

. Carta de um cavalheiro a seu amigo em Edimburgo. Tradução de Plínio J. Smith. In: Manuscrito, Vol. XX, n. 2, out. 1997. p. 15-27.

. Investigação acerca do entendimento Humano. Tradução de José Oscar de Almeida Marques. São Paulo: Editora da Unesp, 1999.

Ensaios morais, políticos e literários. São Paulo: Abril, 1980.

KEMP SMITH, N. The philosophy of David Hume. A critical study of its origins and central doctrines. London: Macmillam Press, 1964.

LIVINGSTON, D. Hume's Philosophy of Common Life. Chicago: Chicago University Press, 1984.

MOURA, C. A. R. de. Crítica humeana da razão. In: Manuscrito. Vol. XX. n. 2. Out. 1997. p. 145-168.

PIERRIS, G. di. Causation as a Philosophical Relation in Hume. In: Philosophy and Phenomenological Research, Vol. LXIV, No. 3, May 2002. p. 502.

SMITH, P. J. O ceticismo de Hume. São Paulo: Loyola, 1995.

STRAWSON, P. F. Skepticism and Naturalism: Some Varieties. London: Methuen \& Co., 1985.

STROUD, B. Hume. London: Routledge \& Kegan Paul, 1977.

O ceticismo de Hume: instintos naturais e reflexão filosófica. In: Skepsis, n. 3, 2008, p. 169-192.

WILLIAMS, M. Unnatural Doubts: Epistemological Realism and the Basis of Scepticism. New Jersey: Princeton University Press, 1997. 